\title{
TECENDO UM POEMA POR ENTRE BLOCOS DE IMAGENS... BLOCOS DE VIDA... FOTOGRAFIA
}

\author{
Manoel Neto ${ }^{1}$
}

\section{Resumo}

O tempo é tempo da natureza. Fina arte fotográfica.

Palavras-chave: Natureza; tempo; fotografia.

\section{Résumè}

Le temps c'est temps de la nature. Fine art photografhie.

Mots clefs: Nature; temps; photografhie.

Uma pérola negra habita no corpo cultural do homem paraense.

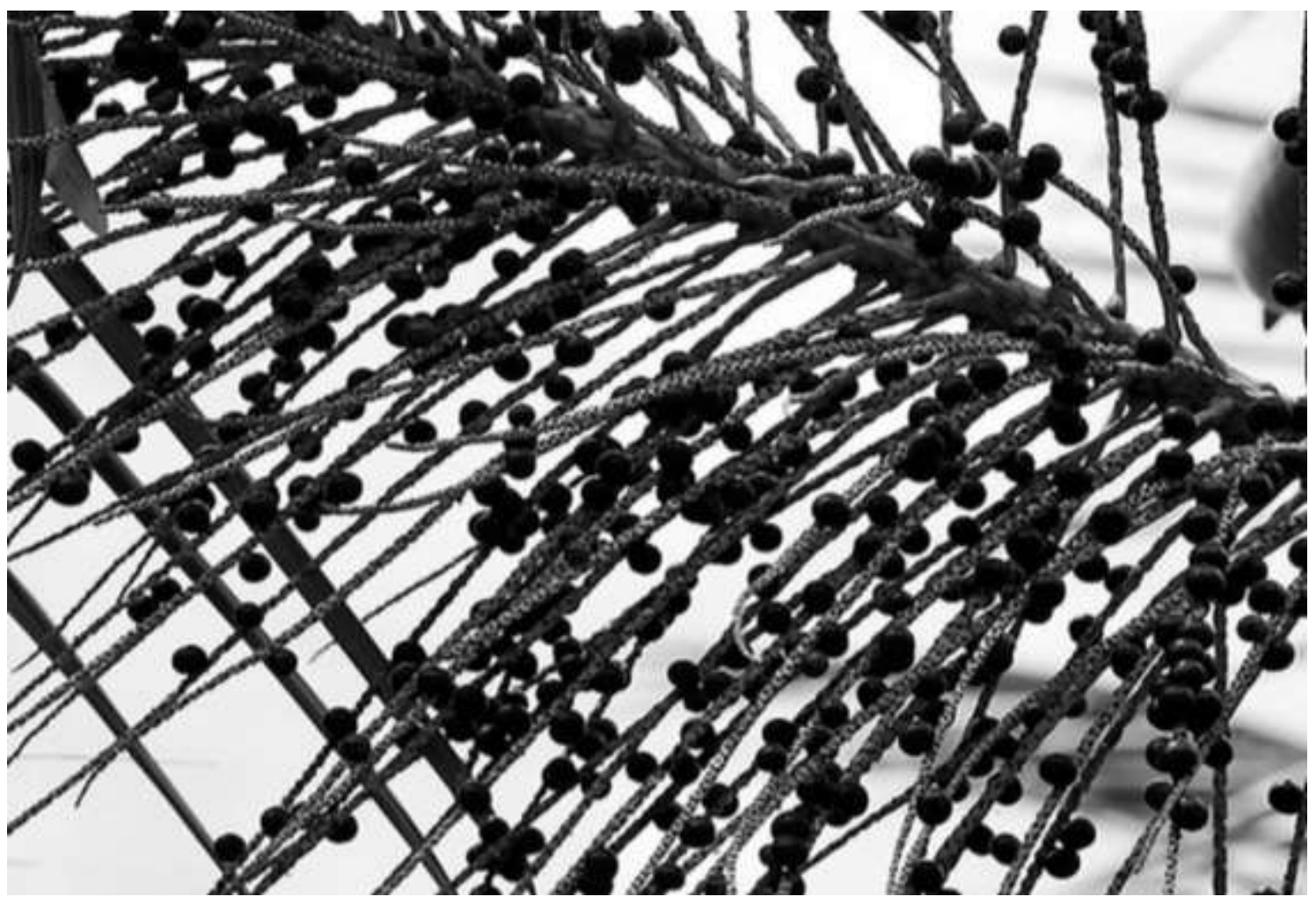

Arquivos de Manoel Neto - São Caetano da Odivelas - Pará2

\footnotetext{
${ }^{1}$ Mestre em Física pela Universidade Estadual de Campinas e doutor pela Universidade Federal do Pará. É pintor e fotógrafo paraense. E-mail: mjneto@ufpa.br

${ }^{2}$ É um município que fica localizado no nordeste paraense.
} 
O Pará é dono de uma beleza selvagem...

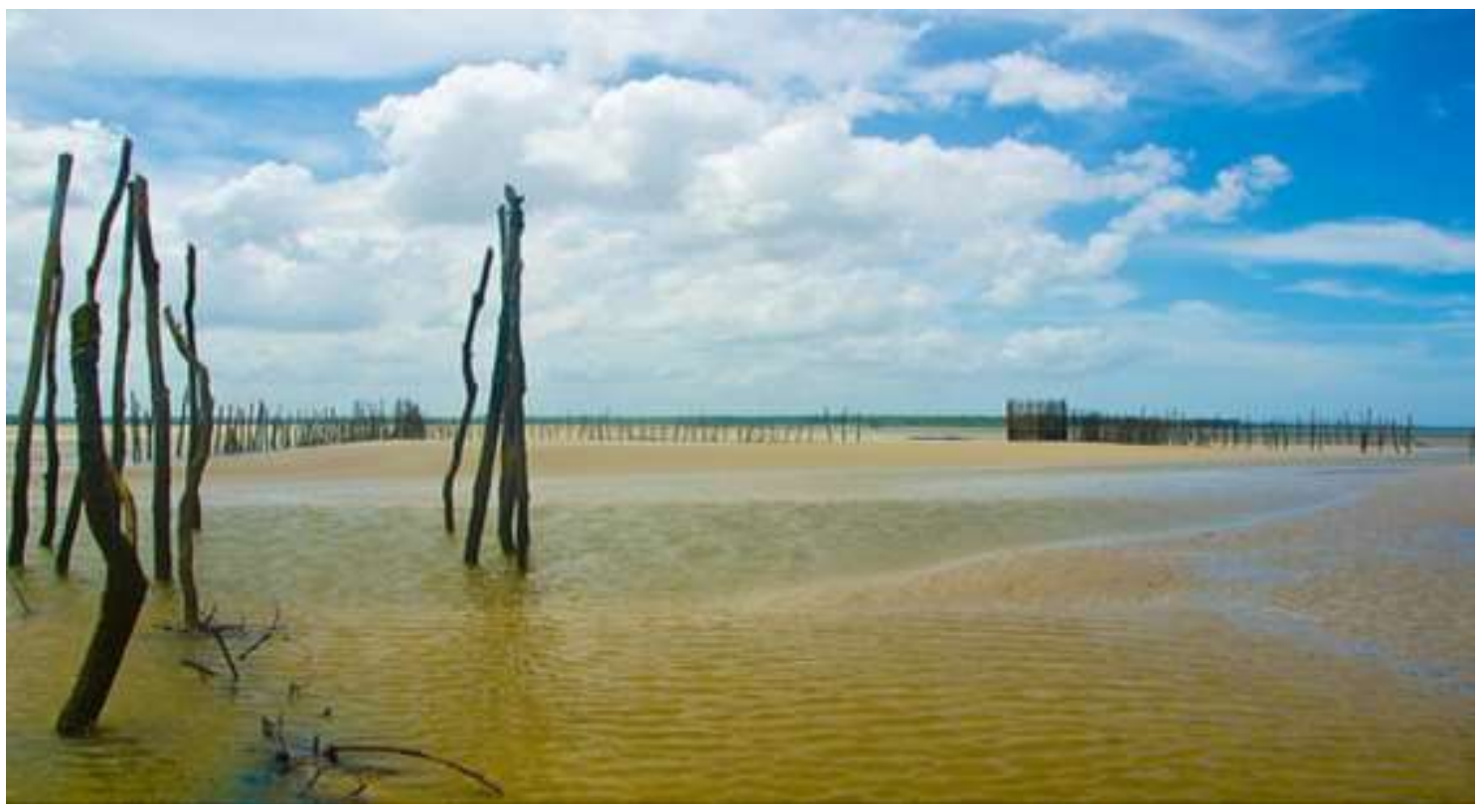

Arquivos de Manoel Neto-São Caetano da Odivelas-Pará

O artista congelou o voo, assim podemos ver o tamanho das asas de um pássaro...Podemos voar com ele...

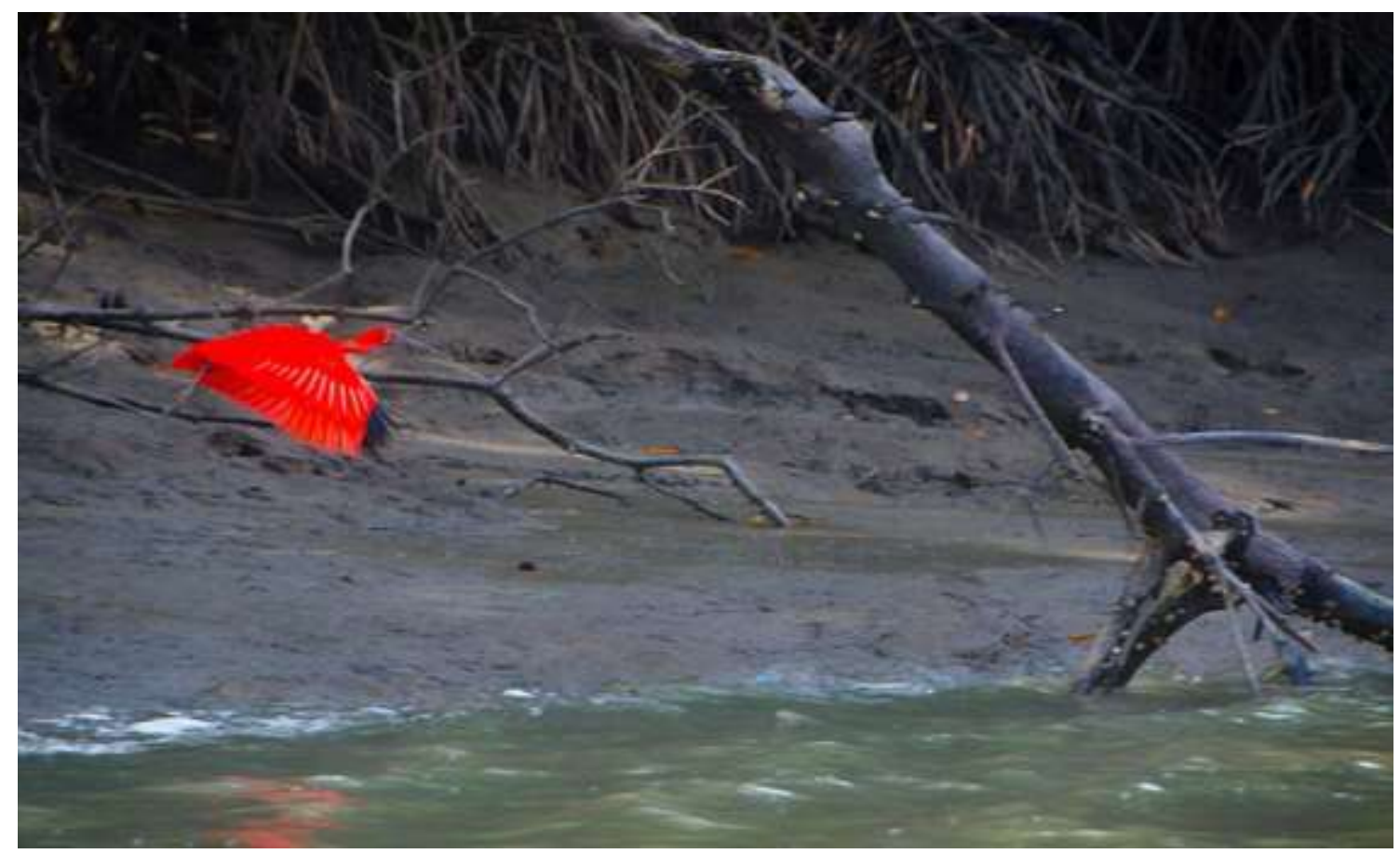

Arquivos de Manoel Neto - São Caetano da Odivelas - Pará 
O pingo de chuva pode ser comparado a uma gota de lágrima...Fotografia do tempo que fica em permanência a partir de um gesto singelo do artista.

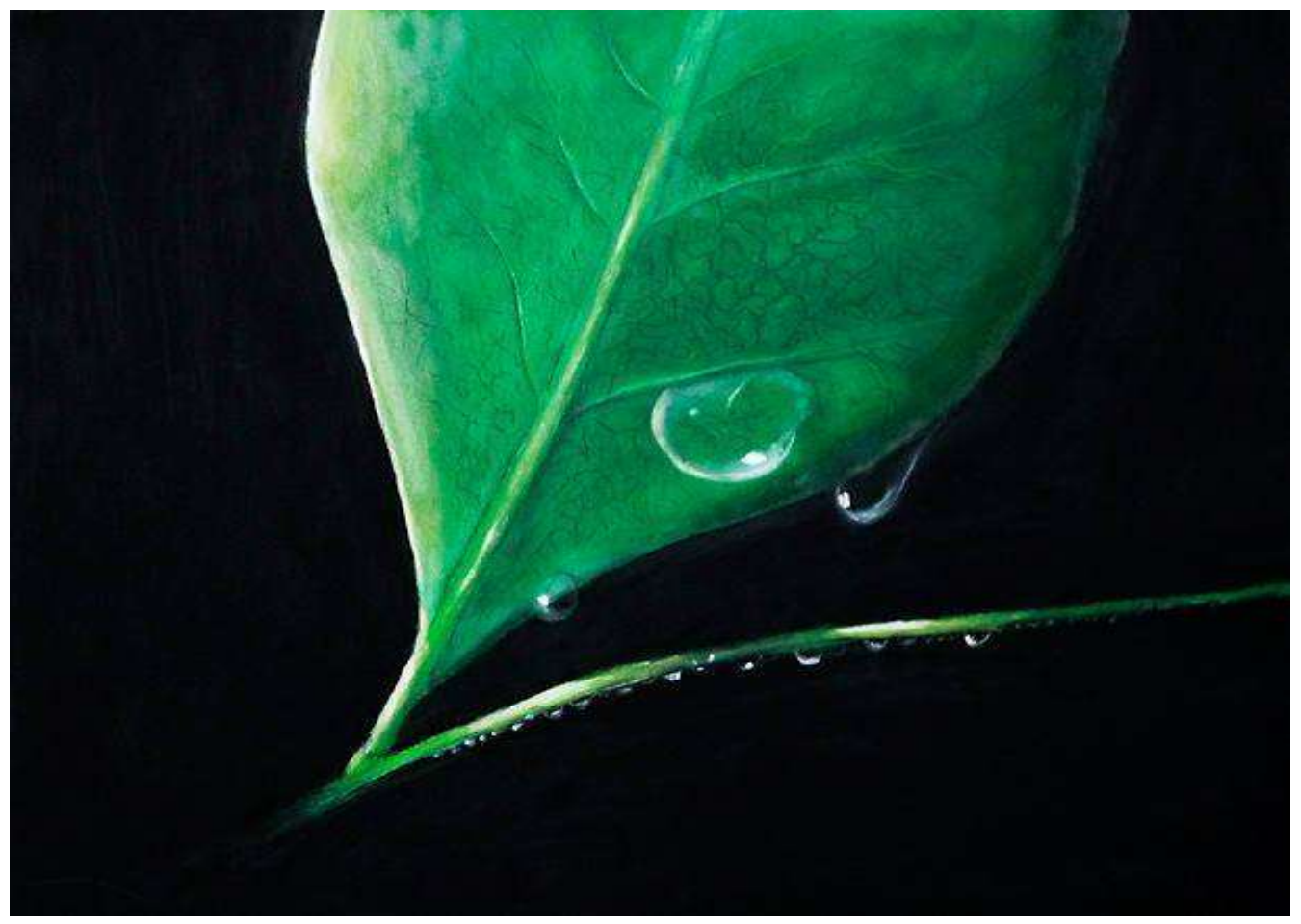

Arquivos de Manoel Neto - São Caetano da Odivelas-Pará

O nomadismo da terra...

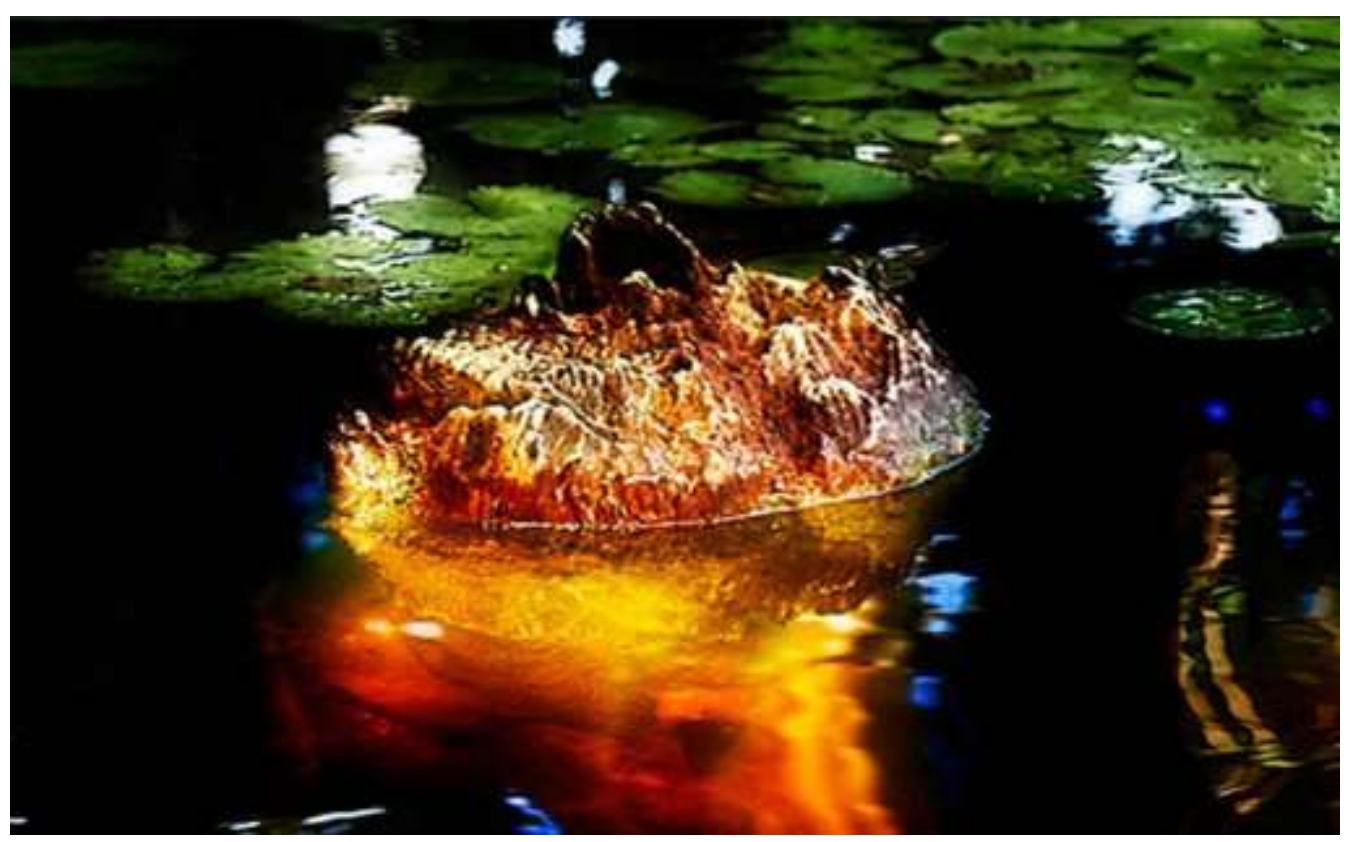

Arquivos de Manoel Neto - Nova Ipixuna ${ }^{3}$

Remando, remando, remando para encontrar outras paisagens...

\footnotetext{
${ }^{3}$ Região Metropolitana de Marabá/Pará.
} 


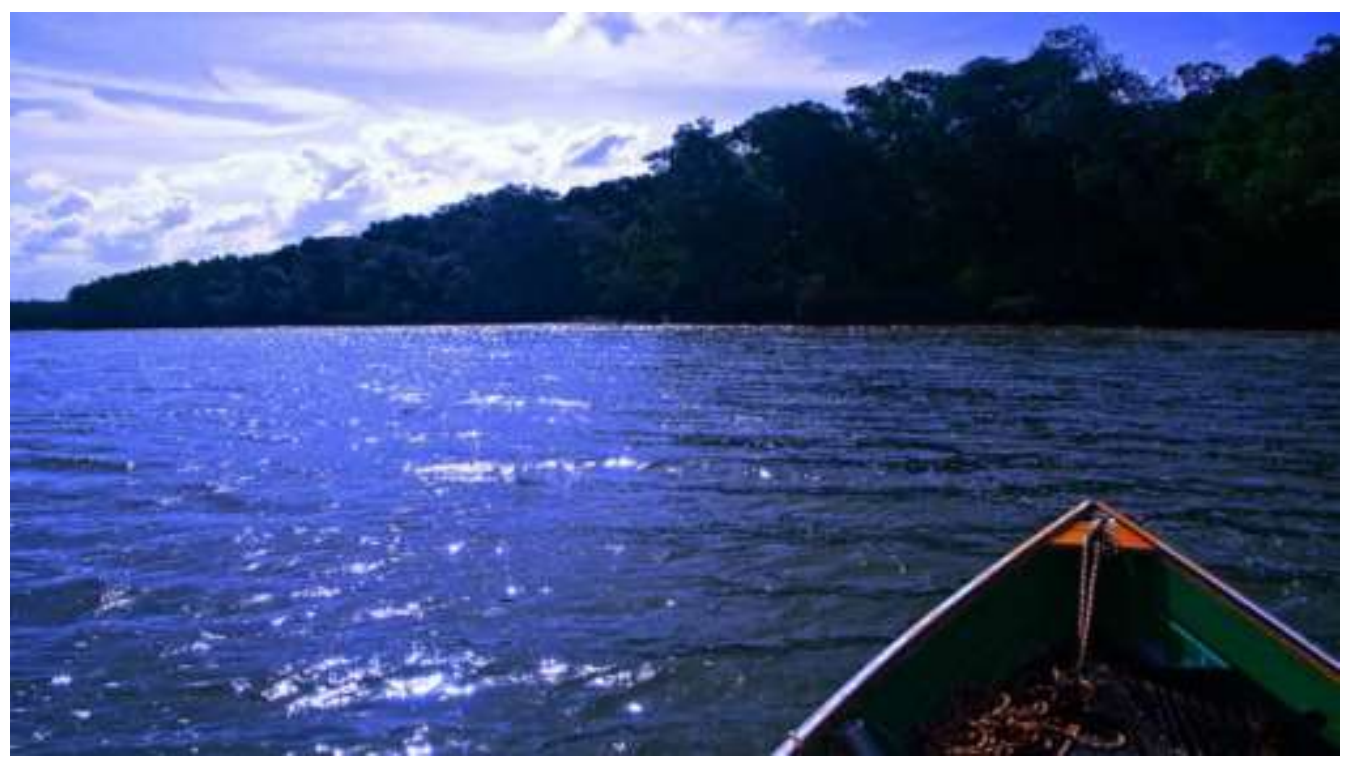

Arquivos de Manoel Neto - Nova Ipixuna

Sussuros da Natureza... Me leva para o lado de lá...

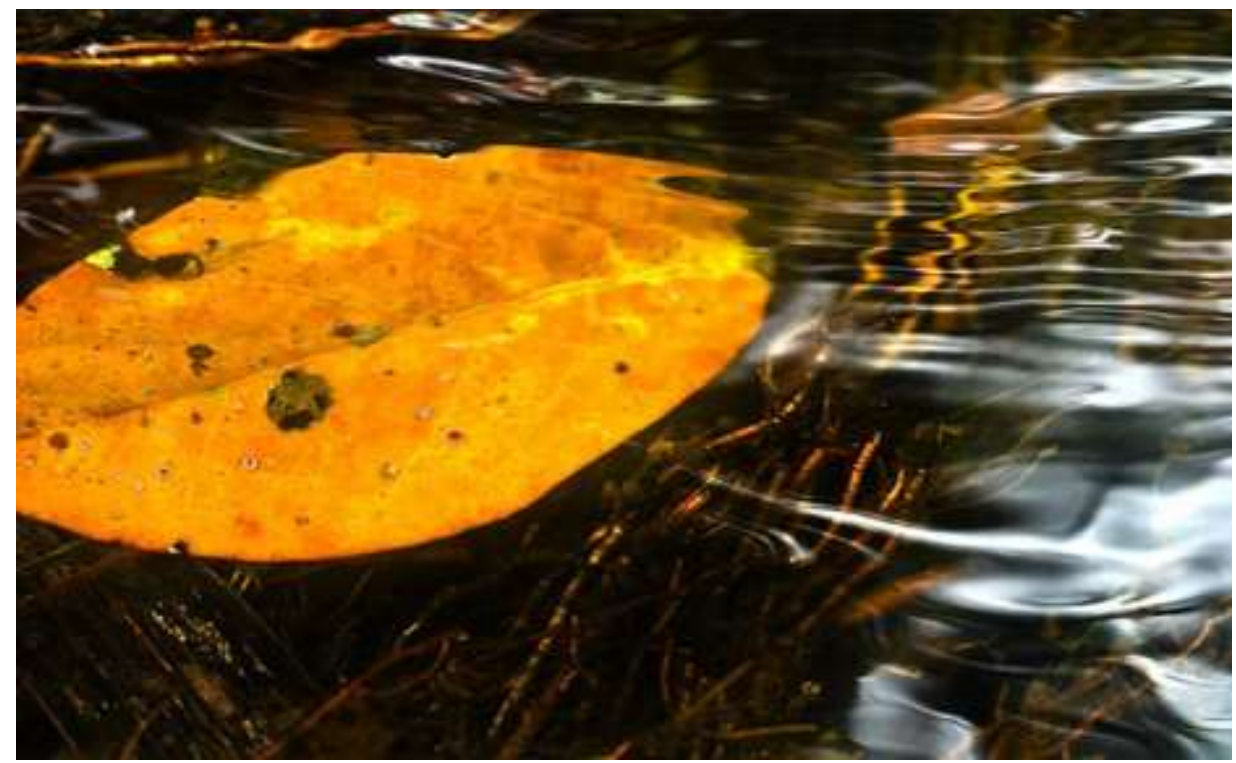

Arquivos de Manoel Neto - Nova Ipixuna

Queres um poema? Como? Estou perguntando se queres um poema: Sim! Um poema para alguns nunca seria um presente...Um presente, um poema!? Quando tudo parece envolvido pelo valor da instrumentalização do capital, da máquina utilitária, um poema como um presente parece desestabilizar o corpo daquele que não consegue perceber o mundo, a vida pelo olhar menor da sensibilidade...A frieza burguesa persiste... mas a emoção, a sensação, a sensibilidade, hum...ela raspa toda a consciência capitalista... e aí me sento a descascar com a natureza... e toco a água, cheiro o tempo, anda nos barcos, escuto o som das águas, ando entre as folhas, descanço entre os braços da vida... Aí fito a mim mesmo e vou pensando...Queres um poema 
de presente para hoje? Eis aqui: Uma folha que se banha nas águas, um gesto que toca a contra pelo o horror atual: Vamos espalhar poesia pelo mundo...

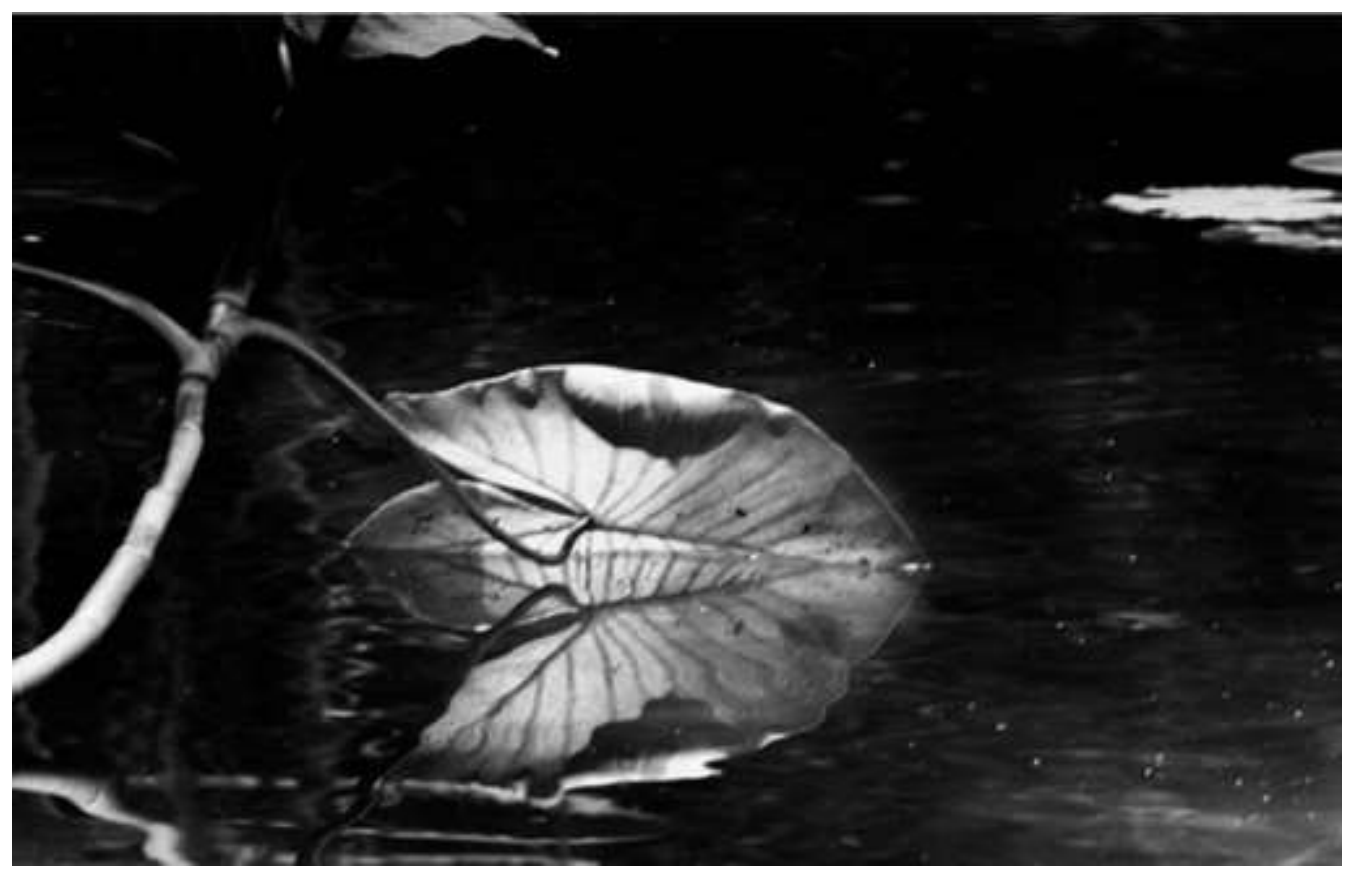

Arquivos de Manoel Neto - Nova Ipixuna 